\title{
JUSTIÇA VIRTUAL TRABALHISTA ${ }^{1}$
}

\section{VIRTUAL LABOR JUSTICE}

Área: Processo do Trabalho. Processo virtual.

\section{Thereza Christina Nahas ${ }^{2}$}

RESUMO: O presente trabalho analisa a evolução da legislação pátria sobre o procedimento virtual adotado pela Justiça do Trabalho, impulsionada pela pandemia provocada pela COVID-19, bem como os efeitos da revolução digital no processo trabalhista, inclusive a privacidade dos atores do processo na rede mundial de computadores.

PALAVRAS-CHAVE: COVID-19. Justiça virtual. Processo e revolução digital.

ABSTRACT: This paper analyzes the evolution of Brazilian legislation on the virtual procedure adopted by the Labor Courts, driven by the pandemic caused by COVID-19, as well as the effects of the digital revolution on the labor process, including the privacy of actors in the process in the world network of computers.

KEYWORDS: COVID-19. Virtual justice. Process and digital revolution.

SUMÁRIO: Introdução 1. O processo digital e sua evolução 2. Os efeitos da pandemia decorrente do COVID-19 3. As audiências pelo sistema de videoconferência 4. A revolução digital na Justiça do Trabalho 5. A boa-fé dos sujeitos da relação jurídica processual 6 . A privacidade digital. Considerações finais. Referências bibliográficas.

\footnotetext{
1 Palestra proferida no $12^{\circ}$ Congresso Internacional de Derecho del Trabajo y de la Seguridad Social, realizado nos dias 21 a 23 de outubro de 2021, promovido pela Universitas Fundación.

2 Pós-doutora e doutora pela Universidad Castilla La-Mancha (campus Albacete/Espanha); doutora pela PUC/SP; acadêmica titular da cadeira n. 43 da Academia Brasileira de Direito do Trabalho; juíza do trabalho titular da $2^{\mathrm{a}}$ Vara do Trabalho de Itapecerica da Serra (SP); professora visitante na PUC/RS. Currículo lattes: http://lattes.cnpq. br/2361402097260893. E-mail: tnahas70@gmail.com
} 


\section{Introdução}

Um dos temas mais apaixonantes em direito processual tem sido o processo virtual e o âmbito do processo nas nuvens, ou seja, seria o procedimento virtual efetivo e eficiente especialmente quando considerado o primeiro grau de jurisdição em que seu ápice estaria na audiência?

\section{O processo digital e sua evolução}

O processo, em uma classificação absolutamente didática e tradicional, caracteriza-se por ser um meio pelo qual se possa solucionar conflito de interesses, ao mesmo tempo que se mostra um instrumento necessário para o exercício de poder e função do Estado, os quais são inerentes ao Poder Judiciário. Dentro dessa perspectiva, os procedimentos capazes de dar corpo ao processo (instituto este absolutamente abstrato) sempre foi cercado de formalidades que dizem respeito, essencialmente, à regra de proteção e de garantia de um direito fundamental do ser humano, que é o de ter assegurado o direito de ser ouvido, quando acusado ou trazido a uma Corte Judiciária, regra esta que foi expressa na Declaração de Direitos Humanos de 10 de dezembro de 1948 em que se previu que toda a pessoa "tem direito a recurso efectivo para as jurisdições nacionais competentes contra os actos que violem os direitos fundamentais reconhecidos pela Constituição ou pela lei" (art. 8. ${ }^{\circ}$ ); entretanto, antes dessa tão festejada Carta Internacional vinculativa a nível supranacional, e consequentemente a nível interno, havia sido aprovado o que foi o primeiro instrumento internacional de direito humanos de caráter geral, a denominada Convenção Interamericana de Direitos e Deveres do Homem (abril de 1948), que, em seu artigo XVIII, dispõe que toda "persona puede ocurrir a los tribunales para hacer valer sus derechos. Asimismo debe disponer de un procedimiento sencillo y breve por el cual la justicia lo ampare contra actos de la autoridad que violen, en perjuicio suyo, alguno de los derechos fundamentales" consagrados constitucionalmente.

Todavia não bastava criar um instrumento de caráter geral, era necessário que se criasse um órgão de controle, o que aconteceu em 1959 com o início das atividades da Comissão Interamericana de Direito Humanos (CIDH) que passou a realizar visitas nos diversos países americanos, a fim de investigar a situação de respeito aos direitos humanos de cada um deles e de buscar a efetividade das normas substantivas. 
O processo é o instrumento efetivo, mas talvez não necessariamente o meio mais justo de se chegar à verdade 3 . Trata-se de um meio democrático para solucionar e prevenir crises, a fim de permitir a imposição do direito material vigente; daí o devido processo legal que lhe é inerente deve assegurar o cumprimento e um dos principais objetivos da função Estatal que é a de pacificar conflitos, seja de forma repressiva, seja de forma preventiva, o que se faz por meio da garantia do acesso à justiça. Por vezes, a busca da tutela estatal pela proteção de direitos somente se torna possível pela via do processo judicial, especialmente em épocas de crises econômica, política ou, porque não dizer, sanitária.

Não foi por outra razão, isto é, pela necessidade que o Estado tem de prestar a tutela judicial, que, em meio às medidas adotadas no estado de exceção decorrente da crise da COVID-19, houve um avanço nunca visto, das medidas que, definitivamente, puderam tornar o processo efetivamente virtual.

A primeira grande revolução processual deu-se quando os procedimentos passaram a ser ditados pela máquina de escrever e, assim, deixaram de ser manuscritos. Nas décadas de 1980 e 1990, iniciou-se a substituição (mais eficiente) das máquinas pelos computadores, que eram equipamentos pesados e se apresentaram como um substituto daquelas máquinas. Daí para frente, a evolução foi cada vez mais rápida e mais tecnológica. Socorro-me do texto publicado por Analu Arnoud que lembra que

[...] a primeira legislação a mencionar a utilização de meio eletrônico para

\footnotetext{
Segundo Flavia Bellolio Carbonell, pode-se condensar o pensamento de Perelman, um dos filósofos que considero que tenha tratado melhor o tema acerca desse conceito tão confuso e com tanta carga de emotiva, através de uma fórmula que pode ser comum aos diversos pensamentos filosóficos. Assim, acentua-se que Perelman examina "las concepciones más corrientes de esta noción a través de la historia del pensamiento filosófico: 1) A cada quien la misma cosa; 2) A cada quien segúnsus méritos; 3) A cada quien según sus obras; 4) A cada quien según sus necesidades; 5) Acada quien según su rango; 6) A cada quien según lo que la ley le atribuye. Estas serán lasfórmulas o reglas de justicia concreta a las que se refiere Perelman (...) El propósito de Perelman es encontrar unafórmula que sea común a las distintas concepciones de justicia, o lo que es lo mismo, uno omás elementos conceptuales que les sean comunes. Para ello, dicha fórmula debe tener unelemento indeterminado o variable, cuya determinación entregará ya una, ya otra concepciónde la justicia. Surge asi la distinción entre la fórmula de justicia formal o abstracta y particular y concreta "la noción común constituirá una definición formal o abstract de justicia y cada fórmula particular o concreta será uno de los innumerables valores de la justicia formal." (BELLOLIO CARBONELL, Flavia. La Regla e Justicia de Perelman y las Teorias de Argumentación Jurídica. Disponível em: (21) (PDF) La regla de justicia de Perelman y las teorías de la argumentación jurídica Flavia Carbonell - Academia.edu. Acesso em: 18 set. 2021).
} 
prática de atos processuais foi a lei 8.245/91, denominada lei do inquilinato. A referida lei, em seu artigo 58, inciso IV, traz a citação pelo fac-smille, desde que prevista em contrato (...) em 1990 surge a lei 9800/99 que passa a admitir o recebimento de petição através de fac-smile ou meio similar. Contudo, para ter validade, as partes deveriam apresentar o original em até cinco dias úteis (...) Em 2001 é instituída a lei 10.259 de 12 de julho de 2001 que estabelece os juizados especiais civeis e criminais no âmbito da Justiça Federal. No parágrafo $2^{\circ}$ do artigo $8^{\circ}$ a referida lei passa a admitir a intimação das partes e o recebimento de petição pela via eletrônico. Ainda em 2001 é editada a medida provisória 2.200/01 que cria a infraestrutura de chaves públicas do Brasil-ICP e regulamenta a assinatura digital e certificação digital. Em 2004 é instituída à Emenda Constitucional de número 45 que acrescenta o inciso LXXXVIII ao artigo $5^{\circ}$ da Constituição Federal: 'A todos, no âmbito judicial e administrativo, são assegurados a razoável duração do processo e os meios que garantam a celeridade de sua tramitação'. ${ }^{4}$

Foi um caminho sem volta para a digitalização, até porque a tecnologia desde a década de 1970 já estava incorporada nas organizações públicas e privadas em uma crescente tendência disruptiva com os meios de produção e serviço: era mais econômico, mais eficiente, o armazenamento de informações mais confiável, além da enorme economia de tempo para realização dos diversos negócios jurídicos, econômicos e sociais.

\section{Os efeitos da pandemia decorrente do Covid-19}

Quando ainda se comemorava os cinco anos de vigência do Código de Processo Civil (2015) com suas regras sobre procedimentos por meios eletrônicos, vem a pandemia da COVID-19 e forçosamente leva a uma ruptura definitiva, necessária e forçada, do meio físico, concretizando-se aquilo que tão somente se admitia "em tese" e que foi nominado pelo Conselho Nacional de Justiça (daqui para frente $\mathrm{CNJ}$ ) de "processo $100 \%$ virtual", isto é, as audiências virtuais, a

4 NEVES DIAS ARNOUD, Analu. De uma análise sobre o processo judicial eletrônico e o PJE (12/2014). Disponível em: De uma análise sobre o processo judicial eletrônico e o PJE - Jus.com. br Jus Navigandi. Acesso em: 18 set. 2021. 
distancia, com os sujeitos processuais e pontos de conexão em locais diversos, provas virtuais tecnológicas, sistema de transmissão direto, enfim, criou-se aquilo que se ansiava, mas não se realizava em razão de vários obstáculos, especialmente culturais: a sala de audiências e sessões virtuais e o balcão de atendimento virtual, únicas peças do puzzle processual que ainda se mantinha a integridade física.

Importa lembrar que, desde o final do século XIX, a "nova escola processual" empenhou-se em ressaltar a característica pública do processo, de modo a desvincular o direito processual do direito material. A nova escola processual promoveu a "desvalorização da figura e da função do juiz e à valorização das formas. A procedure civile, ao tentar negar a importância do juiz, exaltou o formalismo, obscurecendo, por consequência, a verdadeira essência do processo (...) A escola sistemática, mediante a 'publicização' (....) teve o mérito de evidenciar que por meio do processo se exprime a autoridade do Estado"s.

Foi a partir daí e em razão do fundamento dos princípios e necessidades do Estado liberal que se chegou ao avanço da noção e da importância da autonomia processual no sentido de que não se pode atribuir ao processo uma função indiferente ou neutra na sua relação com o direito material e com a realidade social. $\mathrm{O}$ iter percorrido pela teoria processual para chegar-se à maior efetividade possível, atento à máxima que o direito processual deve servir à efetivação das regras e normas adjetivas que permitem a convivência em sociedade e aos direitos mínimos do ser humano, importou que se caminhasse para um degrau além daquele que seria a previsão de ritos especiais adequados a situações jurídicas especiais. Corolariamente, criaram-se mecanismos de acesso aos menos favorecidos economicamente e destinados à tutela aos interesses e direitos transindividuais, permitindo-se a concretude de prestações sociais, bem como instrumentos que pudessem servir a prevenções e a reparações de microlesões.

Houve, também, uma evolução nas medidas de desburocratização do acesso ao poder judiciário, à busca pela efetividade das decisões por meio da previsão de institutos como as tutelas de urgência e provisória que, a partir de 1994, se estenderam a todo processo e procedimento, até que, por fim, as várias microrreformas processuais desaguaram com a proposta de um novo código processual, que entrou em vigor em 2015. Mais técnico e mais bem sistematizado, com uma divisão mais adequada e voltada à efetividade, trazendo

\footnotetext{
MARINONI, Luiz Guilherme; CRUZ ARENHART, Sergio; MITIDIERO, Daniel. Novo Curso de Processo Civil - tutela dos direitos mediante procedimentos diferenciados. São Paulo: Ed. RT, 2017, v. 3, p. 31.
} 
aquilo que se pode nominar de "flexibilidade procedimental". Entende-se, assim, aquelas medidas que permitem "a adaptação - ainda que limitada - do rito processual às peculiaridades do caso concreto. No Código de 2015, parte-se de um procedimento modelo, padrão, autorizando, porém, às partes e ao juiz, a alteração de prazos e da ordem dos atos processuais, a fim de compatibiliza-los às necessidades da situação objeto da tutela" .

Evidentemente que foi com esse espírito que o Conselho Nacional de Justiça (CNJ) teve o impulso de adotar aquilo que faltava ao processo eletrônico, isto é, permitir e viabilizar o sistema informático que viabilizasse que as audiências e as sessões dos Tribunais pudessem ser realizadas normalmente, ainda que os edifícios do fórum estivessem fechados em razão da ordem de isolamento social em meio à pandemia.

Ao que se pôde assistir, foi uma evolução das próprias normas baixadas que tiveram início com plantões extraordinários e ordinários de juízes e de servidores para manterem o serviço mínimo, o que veio com a Resolução 313 de 19 de março de 2020 do CNJ. Nela, houve a previsão, além de outros não menos importantes, de que todo atendimento às partes e aos advogados se faria pela forma remota e "pelos meios tecnológicos disponíveis" (art. $3^{\circ}$ ). Um mês depois, publicou-se nova Resolução, de n. 314, prorrogando a anterior e prevendo a possibilidade de realização de sessões por videoconferência "em substituição às sessões presenciais, fica assegurado aos advogados das partes a realização de sustentações orais, a serem requeridas com antecedência mínima de 24 (vinte e quatro) horas" (art. 5. ${ }^{\circ}$, parágrafo único). A partir de aqui, teve-se início a uma importante fase do procedimento da audiência virtual que viria a ser admitido na primeira instância, esfera esta em que a oralidade e a presencialidade dificilmente (em tese) poderiam ser substituídas pelo meio virtual; porém, a Resolução 317, de 30 de abril de 2020, também vem para contribuir com o iter que acabou desaguando na autorização para que as audiências de primeira instância fossem virtuais, pois permitiu que as perícias em processos em que se discutiam benefícios previdenciários por incapacidade ou assistenciais fossem realizadas virtualmente.

Ibidem, p. 58. 


\section{As audiências pelo sistema de videoconferência}

A verdadeira revolução no processo eletrónico vem com a Resolução 337 de 29 de setembro de 2020 em que se regulou o sistema da videoconferência para audiências e para atos oficiais. O CNJ permitiu que cada Tribunal brasileiro pudesse eleger o sistema que melhor atendesse as suas funções e expectativas, estabelecendo um mínimo, ou seja, um núcleo duro de garantias, que deve ser observado, preservando-se a confidencialidade, privacidade e segurança (art. $2^{\circ} .^{\circ}$ ):

I - a transmissão de áudio e vídeo entre dois ou mais participantes, de forma simultânea e em tempo real;

II - o agendamento de reuniões, sessões e audiências, com possibilidade de envio de convites para os participantes por e-mail;

III - a participação/conexão de convidados pelo uso de navegadores de internet, aplicativo ou programa próprio do fabricante da solução, com segurança de controle de acesso por meio de senha e/ou link gerado pelo organizador;

IV - o compartilhamento de telas, arquivos de conteúdo multimídia entre os participantes;

$\mathrm{V}$ - o controle de ativação das funções áudio e vídeo pelos participantes;

VI - o bloqueio das salas para o ingresso de integrantes mediante aprovação do organizador das audiências, sessões e reuniões;

VII - o envio de mensagens de texto pelos participantes; e

VIII - a gravação das reuniões, audiências e sessões em formato MP4 e outros formatos abertos de arquivos de áudio/vídeo, no dispositivo (computador) de origem do organizador da reunião e/ou em local centralizado disponibilizado pela solução de videoconferência.

Todavia, não bastavam medidas que abrissem o acesso à justiça de qualquer ponto do mundo através do ingresso em salas de videoconferência. Há que se recordar que o Brasil é um país em que a inclusão digital é um desafio, não obstante grande parte da população detenha aparelhos de telefones celulares, o que não significa que estejam necessariamente incluídas digitalmente. Como lembra Janguie Diniz, "para que a inclusão digital aconteça, é preciso três instrumentos básicos: computador, acesso à internet e domínio dessas ferramentas, já que não basta apenas o cidadão possuir um computador conectado à internet para ser considerado um incluído digital. Um total de 102,1 milhões de brasileiros possuem 
acesso à internet no Brasil, de acordo com os dados mais recentes da Pesquisa Nacional por Amostra de Domicílios (PNAD), divulgada em novembro do ano passado pelo Instituto Brasileiro de Geografia e Estatística (IBGE).O número pode até parecer expressivo, mas corresponde a cerca de $49 \%$ da população brasileira. Isso significa que $51 \%$ dos mais de 200 milhões de brasileiros ainda não estão incluídos no mundo digital, o que ajuda a explicar a performance ruim do Brasil em uma outra pesquisa: o Brasil está em $72^{\circ}$ no ranking global de taxa de acesso às tecnologias da informação, segundo o índice Integrado de Telefonia, Internet e Celular"'?

$\mathrm{O}$ acesso precário à internet, a ausência de meios eletrônicos adequados e a falta de informação e educação no uso da rede ${ }^{8}$ levaram o CNJ a publicar a Resolução n. 341 em 07 de outubro de 2020, em um momento em que se organizava o retorno gradual das atividades presenciais. Por essa resolução, criou-se aquilo que foi nominado de "audiências semipresenciais", em que os Tribunais teriam que garantir salas com acesso ao sistema de videoconferência em que todas as medidas de segurança à saúde seriam observadas, ao mesmo tempo que aquele que tivesse qualquer problema de conexão ou de falta de acesso aos meios tecnológicos poderia contar com aqueles que o Estado tem a obrigação de fornecer. Abriu-se uma via importante para a garantia do acesso à justiça, ficando absolutamente visível a concretização, também aqui, da flexibilidade dos meios e da realização dos atos processuais trazidas no CPC de 2015 como uma providência indispensável para garantia do acesso à justiça.

Essa Resolução, imediatamente cumprida pelos Tribunais, além de prever que o local em que as salas deviam estar localizadas e a forma que deviam estar dispostas, trouxe normas procedimentais importantes, como, por exemplo, (i) acompanhamento daquele que fosse ouvido no edifício do fórum por um funcionário da justiça; (ii) envio do link de acesso aqueles que estão fora do

\footnotetext{
7 DINIZ, Jaguiê. A inclusão digital no Brasil ainda é um desafio (19.2.2018). Notícia: UNAMA - Universidade da Amazonia. Disponível em: A inclusão digital no Brasil ainda é um desafio UNAMA. Acesso em: 20 set. 2021.

8 Não obstante o grande número de aparelhos celulares, é certo que eles "não possuem as mesmas funcionalidades que um computador. Fazer trabalhos da escola ou se especializar para uma vaga de emprego são atividades que exigem certo grau de complexidade, demandando um computador e uso ilimitado de dados" (ARAÚJO, Tiago. Inclusão digital no Brasil: em que estágio desse processo estamos? 2020. Disponível em: Inclusão digital no Brasil: em que estágio desse processo estamos? (politize.com.br). Acesso em: 20 set. 2020).
} 
recinto físico, para que acompanhassem as sessões virtuais.

\section{A revolução digital na Justiça do Trabalho}

Foi a Resolução 345 de 09 de outubro de 2020 que pode ser considerada o marco de toda transformação processual, pois tratou do "juízo 100\% Digital", isto é , a partir daqui, há uma verdadeira fase na história da evolução da teoria processual: a presença física das partes e testemunhas já não é necessária, podendo as instruções processuais, repita-se, que era o grande entrave da revolução tecnológica no processo judicial eletrônico, ser realizadas por meios tecnológicos, isto é, todos os atos processuais serão exclusivamente praticados por meio eletrônico e remoto por intermédio da rede mundial de computadores (art. $1 .^{\circ}$ e $\left.\S 1 .^{\circ}\right)$.

Importa dizer que a Justiça do Trabalho, órgão este de caráter nacional, no mesmo diapasão daquilo que regulamentava o $\mathrm{CNJ}$, foi regulamentando a matéria no âmbito específico do Poder Judiciário trabalhista, respeitando-se, em situações específicas, as peculiaridades de cada região, quando dispunha que cada Tribunal, no seu âmbito territorial, pudesse baixar a regulamentação adequada para suas necessidades sempre em respeito às orientações gerais do Tribunal Superior do Trabalho e Conselho Nacional da Justiça do Trabalho e do CNJ.

Há duas questões que me parecem fundamentais, sem menosprezar quaisquer outras, e que ainda causam algum tipo de dúvida e insegurança a alguns sujeitos processuais principais (partes e juízes) ou secundários (testemunhas, peritos, etc.): a primeira relacionada à higidez da colheita da prova; a segunda relativa à privacidade digital, e delas duas decorrem algumas situações jurídicas novas que aparecem no dia a dia, como, por exemplo, a necessidade ou não de transcrição (escrita) de atas de audiência em que a gravação é realizada9 .

\footnotetext{
9 AUDIÊNCIA NÃO REDUZIDA A TERMO. NULIDADE DA SENTENÇA. NECESSIDADE DE RETORNO DOS AUTOS À VARA DA ORIGEM. 1. A legislação processual consagrou, ao longo de séculos de desenvolvimento, a garantia das partes de redução a termo das audiências, isto é, partes e testemunhas são ouvidas, perguntas e reperguntas são feitas pelo juízo e advocacia, para, ao final, o juízo da instrução determinar o que é relevante para constar da memória do ato, tudo sob o crivo do contraditório, já que, neste momento, as partes e seus advogados podem impugnar o conteúdo do que é transcrito. Ademais, a Advocacia é partícipe constante da formação da prova e do processado, constituindo um dos pilares do tripé da Justiça, ao lado da Magistratura e do Ministério Público, consoante art. 133 da Constituição da República, cabendo-lhe papel decisivo nas conclusões que são extraídas da audiência realizada, o que resta completamente inviabilizado quando não há redução a termo do ato. E considerando que a audiência de prosseguimento é a última oportunidade que as partes têm para produzir e apresentar provas, a ausência de termo da audiência resulta em evidente
} 
Quanto às intercorrências processuais, deverão ser decididas nos termos da lei processual em vigor que, ante a maleabilidade do sistema atual, permite que se adapte ao juízo virtual. O negócio processual, previsto no art. 190 CPC, talvez seja o grande instrumento disposto pelo legislador que auxiliará as partes do processo a chegarem a um resultado satisfatório quanto à efetividade do processo. Quando o legislador permite que as partes possam estipular mudanças de procedimentos considerando as peculiaridades da causa em situações jurídicas que admitem a autocomposição, abriu-se um leque para possibilitar que o procedimento se sujeite ao interesse que as partes (juiz, sujeitos ativo e passivo do processo e seus patronos) buscam, com o fim de se promover a tutela efetiva e tempestiva da situação jurídica trazida a juízo, seja ela no âmbito da jurisdição contenciosa ou voluntária.

Não havia ambiente melhor para realização dessa regra jurídica que aquele decorrente da pandemia: o Estado tem o dever de dar uma resposta adequada em tempo razoável e, se um evento extraordinário cause algum embaraço, faz-se mister que, dentro de seu poder de gestão, o Estado encontre meios para colocar em

prejuízo às partes, notadamente ao autor, que teve alguns de seus pedidos julgados improcedentes por falta de prova, em uma situação kafkiana. 2. No encontro entre Direito e tecnologia, entre Direito e informática, é crucial entender e dimensionar que a tecnologia e a informática constituem meio para a consecução de uma finalidade jurídica e não o revés, o Direito não é meio para atingir uma finalidade tecnológica ou informática, sob pena de inversão de valores. 3. Por ofensa aos arts. 712, g, 817, e 828, parágrafo único, da CLT, e arts. 360, V, e 367 do CPC e aos princípios do devido processo legal, contraditório e ampla defesa contidos no art. 5o da CR, cabível, de ofício, o reconhecimento da nulidade da sentença e a determinação de retorno dos autos à origem para redução a termo dos depoimentos prestados pelas partes e dos principais incidentes da audiência, o que deverá ser feito pelo Magistrado de origem" (Proc. No 0020577-13.2020.5.04.0664 (PJe) RO, Relator MARCELO JOSÉ FERLIN D AMBROSO, 23/08/2021.

"Enquanto o CNJ e o TST determinam que o magistrado que quiser degravar a audiência deve mandar que seus próprios servidores o façam, o acórdão da 8a Turma do TRT4 declarou de ofício a nulidade da sentença (sem qualquer provocação das partes) pela falta de transcrição e determinou que eu, outro magistrado, fizesse a degravação. A autoridade de qualquer magistrado está no mérito do processo, isto é, na lide colocada em litígio. Enquanto qualquer magistrado possui liberdade de convicção no que toca ao mérito, as questões administrativas e procedimentais são reguladas pelas corregedorias, sejam as do TRT, as do TST e as do CNJ (...). Juiz não é parte no processo e não se sujeita, pessoalmente, aos comandos do Acórdão. O Juiz tem liberdade de conviç̧ão no mérito e, administrativamente, sujeita-se às Corregedorias. Está repetitivo, há pessoas no Judiciário que não conseguem entender qual a função do magistrado, seja de Primeira ou de Segunda Instâncias, e qual a importância das normas das Corregedorias. Assim, é óbvio que eu não cumprirei a determinação para degravação de audiência”. Proc. No 0020577-13.2020.5.04.0664, TRT/RS, 14/09/2021, Juiz EVANDRO LUIS URNAU. 
marcha o processo. Nada mais que a realização do princípio da instrumentalidade do processo.

\section{A boa-fé dos sujeitos da relação jurídica processual}

A grande preocupação de parte a parte está em como controlar a boa-fé dos sujeitos titulares da relação jurídica material e seus patronos no momento em que atuam em audiência, uma vez que a esfera visual do juiz, que tem o poder de direção do processo, está limitada pelo ângulo da câmara. Isto é, como saber que a testemunha não está mentindo ou que não há repasse de informações do advogado àquele que está depondo? Primeiramente, parece que devemos recuperar o que se havia perdido na atuação nos Tribunais, que é a boa-fé. Em algum momento no tempo, houve uma inversão de valores, de modo que, ao menos, na prática dos fóruns, passou-se a presunção de que a parte, autor ou réu, estaria agindo de má-fé. Juiz e advogados são essenciais à realização da função jurisdicional e devemos presumir que agem com a honestidade que é inerente à função que ocupam. Como já disse,

[...] são variados o aspecto e a compreensão da mentira, e não será o processo eletrônico que viabilizará que os sujeitos processuais possam ser mais ou menos mentirosos ou que utilizem meios para serem orientados durante os depoimentos (...) A testemunha e as partes podem faltar com a verdade não por um ato necessário ou fundado em uma necessidade sua ou de alguém de seu círculo de amigos e família, mas porque tem intenção de enganar, de ocultar, de provocar uma falsa interpretação da verdade. A mentira se verifica ainda quando aquele que fala exagera na verdade dos fatos ou o faz de maneira errônea. Nem sempre um mentiroso tem a favor de si um resultado que the aproveite (...) O mentiroso, em geral, é alguém medroso, frustrado ou inseguro, o que nem sempre se confunde com o fato de querer beneficiar ou prejudicar outra pessoa, mas sim em poder sentir-se confortável consigo mesmo. A difícil tarefa do juiz é de saber qual a linha divisória entre a mentira tolerável e a intolerável; de saber se a mentira contada terá incidência na formação do convencimento ou não. Portanto, a conclusão é que, seja no processo físico ou virtual, a ocorrência de uma prova oral não coincidente com a verdade poderá ser tolerada ou não, dependendo do alcance e força que ela tiver para definir o resultado do processo e a fidelidade da verdade que se busca alcançar para que o julgamento seja justo 
ou simplesmente mais próximo à verdade dos contornos afirmados pelo autor e pelo réu na construção da lide formada" $"$.

\section{A privacidade digital}

Um segundo aspecto que gostaria de considerar é a questão da privacidade digital. $\mathrm{Na}$ internet, há uma enorme quantidade de dados de seu usuário, e, muitas vezes, em ações muito simples, o usuário deixa rastros que o poderão comprometer. Há mecanismos que podem ser criados, e os Tribunais vêm-se empenhando em adotá-los, para que os dados sejam protegidos e a privacidade das partes sejam preservadas. Isso não quer dizer impedir que, eventualmente, uma audiência acabe por ser transmitida ou exposta. As audiências são públicas, e, respeitadas as exceções legais, em tese, não haveria qualquer impedimento para que fossem transmitidas ou que sejam arquivadas em páginas na internet, como ocorrem com as sessões de Tribunais em que, senão todas, a grande maioria está disponível no site do Youtube; portanto, quando um sujeito é parte em um processo, terá que dar seu consentimento para a gravação, mensagem esta que lhe é enviada no início das gravações das sessões.

Parece que o maior problema se refere às situações em que o ponto de conexão se encontra na residência de quem está participando da sessão e, em algumas situações, lhe é determinado que mostre com a câmara o espaço em que está para que todos possam se certificar que não estaria sendo orientado (expressa ou tacitamente) por um terceiro. Aqui me parece que a recusa pode existir, e o fato de ela ocorrer não quer dizer que a parte esteja faltando com a verdade, mas simplesmente que tem direito a defender sua privacidade digital. O usuário da internet tem o direito de escolher qual informação sua poderá tornar-se visível e qual não gostaria que extravasasse as redes. Todavia, uma vez nas redes, a informação e as imagens podem ser utilizadas e veiculadas, dentro dos limites que o próprio autor usuário delimitou. A identidade digital deixa rastros, e, por isso, tudo que se publica na internet pode acabar por comprometer (para o bem e para o mal) seu usuário. Daí a importância de que, antes de se publicar qualquer informação, o usuário deva manifestar-se no sentido de que dados gostaria que ficassem fora do alcance da rede.

Se estiverem participando de uma audiência de natureza pública, os

10 NAHAS, Thereza; FINCATO, Denise; ROSA, Amália. Prática do Processo do Trabalho (do presencial ao virtual). São Paulo: Ed RT, 2020, p. 100-101. 
sujeitos processuais consentem e devem ter ciência de que a sessão é publica, como ocorre em uma sala de audiência física, e que, exceto na fase conciliatória, o procedimento é gravado e ficará publicado na página determinada pelo respectivo Tribunal. Por fim, queria pontuar que a internet e os meios eletrônicos não apenas vêm sendo usados para a realização de audiências, mas também para tornarem efetiva a tutela jurisdicional. Mencionaria, aqui, uma decisão que proferi em um procedimento que estava em fase de execução em que se discutia a eventual existência de fraude ou não, na composição e transformação empresarial. Graças à ferramenta fornecida pela Wayback Machine, site este capaz de explorar mais de 598 bilhões de versões arquivadas na WEB, foi possível conseguir as informações necessárias à solução da questão ${ }^{11}$.

\section{Considerações finais}

Como se pode concluir, os meios tecnológicos são essenciais para garantir um efetivo acesso à justiça e a realização do devido processo legal. Parafraseando a Capelletti, esta nova onda (tecnológica) que se pode assistir de acesso à justiça deve ser entendida como uma fase do avanço da teoria processual no que diz respeito à garantia de meios colocados à disposição do ser humano, para que ele possa recorrer nas situações em que seu direito seja ameaçado, violado ou simplesmente administrado. Nada mais significa que uma técnica processual, das mais avançadas e nunca jamais vista, que permite a realização do acesso e da resposta jurisdicional adequada.

Certamente o juízo 100\% virtual e o atendimento do balcão virtual vão viabilizar que as demandas contidas cheguem ao Judiciário, o que possibilitará que se alcance uma sociedade em que se tenha paz social e respeito às regras jurídicas, seja no âmbito público, privado, individual ou transindividual.

Poderia concluir asseverando que estamos diante daquilo que é uma reforma na estrutura do Poder Judiciário e da cultura jurídica, não necessariamente nas regras jurídicas processuais. Essas estão submetidas ao direito fundamental de acesso à tecnologia e já estão comprovando que podem ser as maiores aliadas para se alcançar a efetividade desse direito e do princípio Constitucional,

\footnotetext{
11 AZEVEDO, Bernard de. Juiza usa Wayback Machine para fundamentar decisão trabalhista (11/8/2021). Notícia disponível em: < Juíza usa Wayback Machine para fundamentar decisão trabalhista (bernardodeazevedo.com) $>$. Acesso em 11/08/2021.
} 
permitindo que nenhuma ameaça ou lesão a direito encontre barreiras para ser exercido. Não é por outra razão que a tecnología vem sendo considerada como um direito fundamental, faltando ao Estado, a partir daqui, implementar políticas públicas para avançar com os meios necessários a se promover a inclusão digital.

Tais considerações constituem um importante passo para o cumprimento do Objetivo 16 da ONU: Paz, Justiça e Instituições Sólidas:

Sin paz, estabilidad, derechos humanos y gobernabilidad efectiva basada en el Estado de derecho, no es posible alcanzar el desarrollo sostenible. Vivimos en un mundo cada vez más dividido. Algunas regiones gozan de niveles permanentes de paz, seguridad y prosperidad, mientras que otras caen en ciclos aparentemente eternos de conflicto y violencia. De ninguna manera se trata de algo inevitable y debe ser abordado. Los altos niveles de violencia armada e inseguridad tienen consecuencias destructivas para el desarrollo de un país, afectan el crecimiento económico y resultan a menudo en agravios arraigados que pueden extenderse por generaciones. La violencia sexual, los delitos, la explotación y la tortura también son fenómenos generalizados donde existen conflictos o no hay Estado de derecho y los países deben tomar medidas para proteger a los sectores que corren más riesgos. Los Objetivos de Desarrollo Sostenible buscan reducir sustancialmente todas las formas de violencia y trabajan con los gobiernos y las comunidades para encontrar soluciones duraderas a los conflictos e inseguridad. El fortalecimiento del Estado de derecho y la promoción de los derechos humanos es fundamental en este proceso, así como la reducción del flujo de armas ilícitas y la consolidación de la participación de los países en desarrollo en las instituciones de gobernabilidad mundial. ${ }^{12}$

A conclusão que se tem é que a iniciativa do Tribunais e do CNJ em promoverem o desenvolvimento do processo virtual é mais uma ação para a realização do acesso à Justiça, o que permite a inclusão e o cumprimento da ODS 16 da ONU.

\footnotetext{
12 Programa de las naciones Unidas para el Desarrollo, disponível em Objetivo 16: Paz, justicia e instituciones sólidas / PNUD. Disponível em: undp.org. Acesso em: 20 set. 2021.
} 


\section{Referência bibliográficas}

ARAÚJO, Tiago. Inclusão digital no Brasil: em que estágio desse processo estamos? 2020. Disponível em: Inclusão digital no Brasil: em que estágio desse processo estamos? (politize.com.br). Acesso em: 20 set. 2020.

AZEVEDO, Bernard de. Juíza usa Wayback Machine para fundamentar decisão trabalhista. 2021. Disponível em: Juíza usa Wayback Machine para fundamentar decisão trabalhista (bernardodeazevedo.com). Acesso em: 11 ago. 2021.

BELLOLIO CARBONELL, Flavia. La regla e justicia de perelman y las teorias de argumentación jurídica. Disponível em: (21) (PDF) La regla de justicia de Perelman y las teorías de la argumentación jurídica | Flavia Carbonell - Academia.edu. Acesso em: 18 set. 2021.

DINIZ, Jaguiê. A inclusão digital no Brasil ainda é um desafio. 2018. UNAMA - Universidade da Amazonia. Disponível em: $\underline{\text { A inclusão digital }}$ no Brasil ainda é um desafio | UNAMA. Acesso em: 20 set. 2021.

MARINONI, Luiz Guilherme; CRUZ ARENHART, Sergio; MITIDIERO, Daniel. Novo Curso de Processo Civil: tutela dos direitos mediante procedimentos diferenciados. São Paulo: Ed. RT, 2017.

NAHAS, Thereza; FINCATO, Denise; ROSA, Amália. Prática do Processo do Trabalho (do presencial ao virtual). São Paulo: Ed. RT, 2020.

NEVES DIAS ARNOUD, Analu. De uma análise sobre o processo judicial eletrônico e o PJE. 2014. Disponível em: De uma análise sobre o processo judicial eletrônico e o PJE - Jus.com.br $\mid$ Jus Navigandi. Acesso em: 18 set. 2021. 